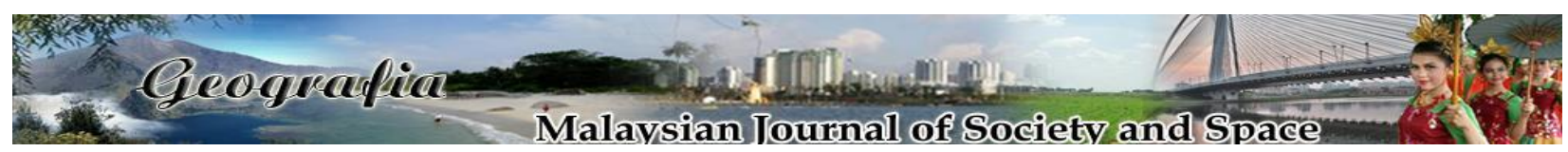

\title{
Strategi pemantapan perpaduan menerusi animasi Upin \& Ipin
}

\author{
Muhamad Syahman Mahdi, Yusmilayati Yunos, Mohd Yuszaidy Mohd Yusoff \\ Pusat Kajian Bahasa, Kesusasteraan \& Kebudayaan Melayu, Fakulti Sains Sosial \& Kemanusiaan, \\ Universiti Kebangsaan Malaysia
}

Correspondence: Yusmilayati Yunos (email: yusmila@ukm.edu.my)

Received: 15 April 2021; Accepted: 11 May 2021; Published: 29 May 2021

\begin{abstract}
Abstrak
Peristiwa 13 Mei 1969 merupakan sebuah kejadian berdarah yang menjadi titik hitam kepada penduduk Malaysia. Selepas tercetusnya peristiwa tersebut lima prinsip Rukun Negara telah digubal untuk dijadikan pegangan dan dasar bagi penyatuan rakyat yang berbilang kaum di negara ini. Bagi melestarikanya, setiap prinsip yang terkandung dalam Rukun Negara perlu diperkasakan dan diamalkan melalui amalan perpaduan bagi menjamin kestabilan sosial dalam membina sebuah negara yang berdaulat dan dihormati. Antara objektif kajian ini adalah untuk mengenal pasti kesedaran dan kepentingan Rukun Negara, dan seterusnya melihat kelebihan animasi Upin \& Ipin dalam memberi sumbangan yang positif bagi pembentukan perpaduan sosial masyarakat di Malaysia. Animasi ini dianalisis dengan menggunakan pendekatan prinsip Rukun Negara yang kelima iaitu Kesopanan dan Kesusilaan. Dapatan kajian menunjukkan keempat-empat hasil dapatan iaitu kesejahteraan, perpaduan, bahasa dan media massa saling berkaitan antara satu sama lain dalam membentuk strategi pemantapan dan pengukuhan perpaduan melalui prinsip Kesopanan dan Kesusilaan. Kejayaan mengadunkan keempat-empat dapatan ini telah menghasilkan sebuah jalan cerita animasi yang baik bagi menyedarkan masyarakat tentang kepentingan memahami dan menghayati Rukun Negara. Justeru, implikasi kajian ini diharapkan dapat menjadi titik awal terhadap pembentukan perpaduan yang dinamik menerusi Rukun Negara bagi membentuk sebuah masyarakat Malaysia yang bersatu padu dan berpendirian teguh.
\end{abstract}

Kata kunci: Animasi, Kesopanan dan Kesusilaan, perpaduan, Rukun Negara, 13 Mei 1969, Upin \& Ipin 


\title{
Strategy to strengthen unity through Upin \& Ipin animation
}

\begin{abstract}
The incident of 13 May 1969 was a bloody incident that became a black spot for the people of Malaysia. After the event, the five principles of Rukun Negara were formulated to be the holding and policy for the unification of the multi-racial people in this country. To sustain it, every principle contained in the Rukun Negara must be strengthened and practiced through the practice of unity to ensure social stability in building a sovereign and respected nation. Among the objectives of this study is to identify the awareness and importance of Rukun Negara, and further see the advantages of Upin \& Ipin animation in providing a positive contribution to the formation of social unity in Malaysia. This animation is analysed using the approach of the fifth principle of Rukun Negara, namely Decency and Morality. The findings of the study show that the four findings, namely well-being, unity, language and mass media are interrelated with each other in formulating strategies to strengthen and strengthen unity through the principles of Decency and Morality. The success of blending these four findings has produced a good animated storyline to make the community aware of the importance of understanding and appreciating the Rukun Negara. Thus, the implications of this study are expected to be the starting point for the formation of dynamic unity through the Rukun Negara to form a Malaysian society that is united and has a strong stance.
\end{abstract}

Keywords: Animation, Courtesy and Morality, unity, Rukun Negara, May 13, 1969, Upin \& Ipin

\section{Pengenalan}

Kewujudan masyarakat majmuk di Malaysia merupakan satu anugerah Tuhan yang mempunyai hikmah tersendiri. Oleh yang demikian, kepelbagaian yang dimiliki ini seharusnya dipelihara oleh setiap kaum dan seharusnya setiap rakyat mengambil peluang yang diberikan untuk mengenali hati budi satu sama lain. Sebagai rakyat Malaysia yang telah mencapai kemerdekaan selama 63 tahun, setiap lapisan masyarakat seharusnya memahami dan mempelajari serta mengetahui hakikat kewujudan setiap kaum di negara ini agar terjalin ikatan yang mesra melalui persefahaman dan tolak ansur. Setiap harus bersama-sama membangunkan negara pada masa kini dan masa akan datang, serta menjadikan peristiwa yang telah berlalu sebagai sejarah yang berfungsi sebagai tunjang pembangunan yang mantap, beridentiti, jitu dan tidak rapuh dimamah zaman.

Rukun Negara merupakan salah satu ideologi negara Malaysia yang telah diwujudkan ekoran daripada peristiwa rusuhan kaum pada 13 Mei 1969. Ideologi ini telah digubal semasa negara sedang berada di bawah pimpinan MAGERAN, dan badan yang bertanggungjawab menggubalnya ialah Majlis Perunding Negara (MPN). Pada 27 Januari 1970, sebuah rundingan dan kata sepakat telah dipersetujui untuk mencipta satu ideologi yang dikenali sebagai Rukun Negara sewaktu mesyuarat pertama Majlis Perundingan Negara ketika itu. Oleh yang demikian pihak kerajaan telah berpendapat bahawa negara ini memerlukan peranannya dalam memastikan nilai-nilai yang ingin diterapkan dalam memupuk perpaduan dalam kalangan rakyat boleh dilaksanakan. Lantaran itu, beberapa dasar telah diperkenalkan oleh pihak kerajaan dalam membentuk dan memantapkan perpaduan yang meliputi penubuhan dasar sosial, ekonomi dan 
politik. Tidak ketinggalan Rukun Negara turut dijadikan sebagai salah satu dasar yang memainkan peranan sangat penting dalam memastikan dan memupuk semangat perpaduan masyarakat berbilang kaum di Malaysia.

Terdapat lima objektif Rukun Negara iaitu, mencapai perpaduan yang erat dalam kalangan masyarakat, memelihara cara hidup demokrasi, membentuk masyarakat yang adil supaya kemakmuran dinikmati bersama secara adil dan saksama, membentuk masyarakat bersifat liberal, terutamanya terhadap kebudayaan masing-masing dan membina masyarakat yang progresif dengan sains dan teknologi. Menerusi objektif yang kelima iaitu membina masyarakat yang progresif dengan sains dan teknologi, maka syarikat produksi Les' Copaque telah menerbitkan siri animasi Upin \& Ipin yang dilihat sebagai sebuah animasi berpengaruh dan berperanan besar dalam menyebarluaskan maklumat dan agenda perpaduan kepada masyarakat Malaysia terutamanya dalam menyanjung dasar Rukun Negara.

Namun, semenjak akhir-akhir ini, terdapat pelbagai pihak yang gemar melontarkan isu-isu yang berkaitan dengan kemasyarakatan terutamanya perpaduan, kesopanan dan kesusilaan. antara mereka ada yang berniat baik, yakni untuk meningkatkan perpaduan, tetapi ada juga yang bertujuan untuk kepentingan fahaman politik masing-masing. Semangat yang terdapat dan terkandung dalam lima prinsip Rukun Negara ini mempunyai keistimewaannya dan wajar menjadi pegangan khususnya dalam kalangan generasi muda dan belia. Dalam prinsip tersebut mengandungi unsur-unsur semangat dan nilai-nilai murni ke arah pemupukan perpaduan tanpa mengira usia dan latar belakang bangsa serta budaya. Golongan muda seharusnya mengambil iktibar dalam memperkasakan dan mendaulatkan Rukun Negara. Namun, kini zaman yang telah berubah, dan bagi menongkah arus perubahan ini, prinsip-prinsip Rukun Negara sebenarnya telah diterapkan dalam media elektronik secara tidak langsung melalui siri animasi Upin \& Ipin melalui pendekatan dan medium yang berbeza dan lebih pantas untuk disampaikan kepada khalayak penonton.

\section{Tinjauan literatur}

Kewujudan isi-isu politik, ekonomi dan sosiobudaya selepas Malaysia mencapai kemerdekaan perlu dihadapi oleh pihak kerajaan kesan daripada perubahan daripada segi kondisi masyarakat di negara ini. Wujudnya masalah dan krisis ini adalah kerana masyarakat Malaysia mempunyai penduduk yang berbilang kaum. Selain daripada itu, pengaruh serta anasir daripada pihak luar yang cuba untuk mengganggu kedaulatan negara turut menjadi puncanya. Antara peristiwa yang pernah dialami oleh Malaysia adalah seperti Zaman Darurat pada tahun 1948-1960, Konfrontasi Indonesia 1963, dan Rusuhan Perkauman pada 13 Mei 1969 yang telah memberi impak negatif kepada negara. Kesannya ialah penggubalan Akta Mesin Cetak dan Penerbitan 1984 yang telah memansuhkan Akta Mesin Cetak 1948 dan Akta Kawalan Penerbitan Diimport 1958. Kandungan akta tersebut telah mengemukakan garis panduan yang harus dipatuhi, selain bertujuan untuk mengawal semua kandungan penerbitan agar tidak menyentuh perkara-perkara yang sensitif seperti isu perkauman yang boleh mencetuskan kekeliruan dan mengancam keselamatan negara (Muliyadi Mahamood, 2007). Melalui garis panduan yang terdapat dalam akta tersebut telah menggalakkan para penerbit filem dan siri animasi untuk menghasilkan cerita yang memaparkan elemen kerjasama, keharmonian, perpaduan dan kesejahteraan kaum-kaum di Malaysia. Hal ini jelas terbukti apabila kebanyakan filem dan siri animasi banyak menggunakan watak berbangsa Melayu, Cina dan India bagi menerajui plotnya 
Rukun Negara merupakan pegangan dan panduan untuk menyatukan rakyat di bawah payung bangsa Malaysia. Namun, kita masih berhadapan dengan tindakan biadab segelintir warganegara yang melakukan provokasi, seperti mahu menukar Jalur Gemilang, memijak gambar Perdana Menteri serta memaki hamun para pemimpin negara. Pelbagai ancaman datang bersilih ganti hasil gerakan golongan ekstremisme yang selalunya digandingkan dengan bibit-bibit keganasan terutamanya dalam ruang politik dan agama sehingga menyebabkan kehilangan nyawa. Justeru, walaupun kita mengejar arus kemajuan namun, Rukun Negara perlu sentiasa dihayati oleh rakyat kerana pembentukannya adalah dengan mengikut acuan masyarakat Malaysia dan tujuan utamanya adalah untuk memperkukuhkan ketahanan dan keamanan negara. Hasilnya, Malaysia naik empat tangga dalam Indeks Keamanan Global [IKG] 2018 dengan menduduki kedudukan ke25 berbanding ke-29 pada tahun 2017 (Hadijah Johari, \& Anas Suzastri Ahmad, 2019).

\section{Metodologi}

Kajian ini dilakukan untuk mengenal pasti tentang kesedaran dan kepentingan Rukun Negara dan seterusnya melihat kelebihan animasi Upin \& Ipin dalam memberi sumbangan yang positif dalam membentuk perpaduan sosial masyarakat di Malaysia melalui prinsip Rukun Negara yang kelima iaitu Kesopanan dan Kesusilaan. Metodologi kajian ini ialah menggunakan pendekatan kualitatif. Kajian kualitatif melibatkan proses penyiasatan dan pentafsiran untuk memahami isu atau masalah sosial dengan menonjolkan keunikan persekitaran kajian. Kajian kualitatif ini biasanya bersifat subjektif serta mengetengahkan peranan pengkaji sebagai pentafsir secara berterusan. Pada dasarnya kajian yang bersifat kualitatif adalah untuk mendapatkan data dan membuat pentafsiran dengan menggunakan kajian kepustakaan untuk menganalisis kandungan teks. Oleh sebab itu, kajian kualitatif dibuat secara holistik bagi memaparkan elemen yang dikaji dalam persekitaran untuk menampakkan perspektif kajian.

Sebagai rakyat Malaysia yang bertanggungjawab, prinsip-prinsip utama Rukun Negara seharusnya telah difahami dan dihayati. Penghayatan dan kefahaman terhadapnya akan melahirkan masyarakat Malaysia yang teguh dan bersatu padu. Terdapat lima prinsip dalam Rukun Negara yang perlu diketahui dan ditanam dalam jiwa masyarakat Malaysia iaitu:
i. $\quad$ Kepercayaan kepada Tuhan
ii. Kesetiaan kepada Raja dan Negara
iii. Keluhuran Perlembagaan
iv. Kedaulatan Undang-undang
v. Kesopanan dan Kesusilaan.

Kesopanan secara dasarnya dapat dilihat berdasarkan tingkah laku bahasa dan bukan bahasa. Perilaku Bahasa merujuk kepada kegiatan berbahasa secara lisan atau tulisan, manakala perilaku bukan bahasa pula berkaitan dengan tingkah laku yang diperlihatkan tubuh badan manusia. Kesopanan dalam kajian ini lebih berfokus kepada perilaku bahasa. Bahasa terdiri daripada bahasa halus dan bahasa kasar. Bahasa halus bukan hanya bahasa diraja, malahan bahasa bersopan atau berlapik juga dikatakan sebagai bahasa halus. Terdapat empat kategori kaedah tidak langsung yang digunakan oleh orang Melayu untuk menyampaikan sesuatu perkara yang boleh dikaitkan dengan kesopanan melalui bahasa berlapik, iaitu serkap jarang (beating about the bush), kiasan (imagery), berbalik (contradicting), dan orang perantaraan (surrogate). Namun bahasa perbincangan, perbahasan dan perundingan pula boleh digolongkan sebagai bahasa terpelajar, kerana ada ketikanya wujud konflik ketika penggunaan bahasa tersebut. Ini bermakna semua 
kelainan bahasa tersebut di atas ditandai dengan kesopanan selain daripada bahasa kasar (Noor Hasnoor Mohamad Nor, Eizah Mat Hussain, \& Ahmad Ramizu Abdullah, 2019).

Setiap lapisan masyarakat Malaysia seharusnya mempunyai penghayatan yang tinggi terhadap Rukun Negara, khususnya prinsip Kesopanan dan Kesusilaan. Hal ini kerana prinsip ini merupakan landasan yang penting bagi setiap masyarakat yang menganuti pelbagai agama dan bangsa untuk terus kekal menghormati antara satu sama lain. Agama merupakan ciri yang penting dalam kehidupan manusia kerana tanpa agama sesebuah lapisan masyarakat atau individu akan mengalami keruntuhan moral. Malaysia merupakan sebuah negara yang bebas dan demokrasi dalam menganuti sesebuah agama. Kaum-kaum di Malaysia menganuti pelbagai agama seperti agama Islam, Taoisme, Buddhisme, Hinduisme, Kristian, Confucianisme dan lain-lain. Berdasarkan kepada kepelbagaian agama ini, setiap agama yang dianuti dapat membimbing tindakan seseorang untuk berbuat baik dan menghindari perbuatan jahat. Dalam Perlembagaan Persekutuan Malaysia telah menetapkan agama Islam sebagai agama rasmi dan agama lain bebas diamalkan oleh rakyat bukan Islam. Kebebasan beragama membolehkan setiap individu berpegang kepada kepercayaan yang diyakini dan patuh kepada ajaran agama tersebut. Kesopanan dan Kesusilaan turut diterapkan dalam ajaran setiap agama. Setiap bangsa juga telah ditanamkan sifat untuk menghormati dan berkasih sayang antara satu sama lain.

Kajian penulisan ini tertumpu kepada beberapa episod yang ditayangkan dalam animasi Upin \& Ipin. Antaranya episod Skuad Bebas Denggi, Berpuasa Bersama Kawan Baru, Terima Kasih Cikgu, Puasa, Nikmat,, Kawalan Pergerakan dan montaj animasi Upin \& Ipin yang bertajuk Upin \& Ipin - Rukun Negara,

\section{Dapatan dan perbincangan}

Menerusi animasi Upin \& Ipin, prinsip Kesopanan dan Kesusilaan telah dijadikan sebagai panduan kajian ini. Prinsip ini mengandungi huraian mengenai sikap bersopan santun dan tatasusila dalam diri setiap rakyat Malaysia. Selain itu, prinsip ini turut menyentuh tentang personaliti dan tingkah laku seseorang rakyat. Sebagai contoh, bangsa Melayu amat terkenal dengan sifat lemah lembut dan sopan santunnya. Kehidupan seharian sangat dipengaruhi oleh persekitaran masyarakatnya. Kebiasaannya ini telah menjadi amalan turun temurun zaman berzaman yang diwarisi daripada nenek moyang mereka. Tak lapuk dek hujan, tak lekang dek panas, begitulah amalan-amalan warisan itu tetap diamalkan walaupun arus kemodenan telah lama menyerapi kehidupan masyarakat Melayu.

Kesopanan dan kesusilaan juga berkait rapat dengan tutur kata seseorang, lantas prinsip ini menjamin penggunaan bahasa yang lembut yang melahirkan perbuatan halus. Hasilnya hubungan baik sesama kaum dapat terus kekal dan lestari. Siri animasi Upin \& Ipin telah menyentuh peranan bahasa Melayu sebagai bahasa perpaduan dalam kalangan masyarakat di Malaysia yang berbilang kaum dan beragam bangsa ini. Peranan dasar bahasa juga disentuh bagi membuktikan bahawa bahasa Melayu merupakan bahasa penting dan mengalami proses perancangannya. Bahasa Melayu juga telah didasarkan sebagai bahasa kebangsaan dan bahasa rasmi seperti yang terkandung dalam perkara 152 Perlembagaan Persekutuan. Daripada keseluruhan cerita dalam siri animasi Upin \& Ipin yang berdurasi 30 minit ini telah menggunakan bahasa Melayu yang mudah difahami bagi menggambarkan kepada khalayak bahawa bahasa Melayu ini boleh diterima oleh setiap lapisan masyarakat di Malaysia. Melalui watak Mei Mei dan Rajoo juga dilihat fasih berbahasa Melayu walaupun kadang kala kedengaran agak pelat sedikit. Namun semangat untuk bertutur dalam bahasa Melayu itu yang harus dipuji kerana secara tidak langsung ia akan menarik minat kaum 
lain untuk menonton siri animasi Upin \& Ipin ini bagi mendalami lagi etika dan nilai-nilai murni yang ada pada masyarakat Melayu Malaysia.

Bahasa Melayu turut melambangkan kesantunannya dengan peningkatan ilmu dan kepenggunaannya boleh dijadikan sebagai kayu ukur kepada kesantunan bahasa Melayu tersebut. Bahasa Melayu mencakupi ciri-ciri dan nilai-nilai berbahasa seperti bersifat budi bahasa, beradab dan memiliki nilai-nilai yang baik untuk diterapkan dalam kehidupan rakyat yang berbilang bangsa dengan menggunakan bahasa Melayu sebagai bahasa penghantar dalam kehidupan mereka. Perkara ini jelas ditonjolkan dalam siri animasi Upin \& Ipin iaitu penggunaan bahasa Melayu dalam kehidupan mereka jelas semasa musim perayaan dan sebagainya. Tradisi kunjungmengunjungi antara jiran tetangga yang berbilang kaum dengan berkomunikasi dalam bahasa Melayu turut dipaparkan dalam siri animasi ini. Begitu juga amalan bergotong-royong, menghadiri majlis perkahwinan dalam budaya pelbagai kaum serta sambutan rumah terbuka yang diadakan di tempat masing-masing. Amalan bergotong-royong dalam masyarakat menunjukkan sikap bermasyarakat yang baik dan harmoni. Mereka berkomunikasi dalam bahasa Melayu iaitu bahasa yang mudah difahami. Selain itu, penggunaan bahasa Melayu turut dijadikan sebagai bahasa perhubungan antara kaum. Dengan menguasai komunikasi berbahasa ini, hubungan yang baik akan mudah terjalin. Amalan hormat-menghormati dan sikap toleransi antara kaum perlu diamalkan sekiranya kita ingin melihat perpaduan terlaksana di negara Malaysia. Contoh sedemikian dapat dilihat dalam animasi Upin \& Ipin yang memaparkan watak Mei Mei, Jarjit, Rajoo, Uncle Muthu dan Uncle Ah Tong. Watak-watak yang ditunjukkan ini memberi gambaran bahawa perpaduan kaum terjalin melalui hubungan baik masyarakat di Kampung Durian Runtuh.

Seterusnya dalam menyemai semangat perpaduan melalui prinsip Rukun Negara ini, akhlak kemuliaan dan kesejahteraan yang terdapat dalam huraian Kesopanan dan Kesusilaan merupakan sebuah hubungan yang baik dan terjamin sekiranya setiap daripada rakyat Malaysia mengamalkan prinsip ini. Hubungan baik yang terjamin ini akan mengelakkan diri daripada menyentuh perkara-perkara yang sensitif dan menjamin kesejahteraan setiap lapisan masyarakat. Melalui animasi Upin \& Ipin, banyak aktiviti kehidupan dan budaya yang dipamerkan dalam animasi ini. Antaranya ialah Upin, Ipin serta rakan-rakannya menjalani proses pembelajaran di dalam kelas bersama dengan Cikgu Melati di Tadika Mesra. Hasil daripada pemerhatian dapat dilihat watak Upin, Ipin dan rakan-rakannya merupakan manifestasi gambaran kanak-kanak di Malaysia yang mendapat pendidikan awal mereka di taman bimbingan kanak-kanak Tadika Mesra atau dikenali sebagai sekolah tadika. Sesi pembelajaran yang berlangsung turut menerapkan pendidikan secara formal dan tidak formal berdasarkan silibus yang menekankan konsep membaca, mengira dan menulis selain daripada aktiviti luar kelas bagi memupuk akhlak, nilai kemuliaan dan kesejahteraan sesama insan. Pendidikan ini penting kerana pada usia sebegini kanak-kanak akan dipantau proses pembelajaran dan penerimaan mereka terhadap perkara yang dilihat di sekeliling mereka.

Selain itu, penonton turut dapat melihat paparan imej positif dan bersih daripada watak Kak Ros, Upin dan Ipin terhadap layanan yang diberikan kepada nenek mereka iaitu Opah. Mereka memberikan layanan yang mesra serta menggunakan perkataan yang sopan semasa bertutur dengan orang yang lebih dewasa. Percakapan adalah elemen dan cara penting dalam hubungan sosial, lantaran itu animasi ini telah mengambil kira faktor utama melalui percakapan yang dipenuhi dengan sifat kejujuran yang menjadikan setiap watak dalam animasi ini dapat diterima oleh masyarakat. Secara tidak langsung ia akan memberikan imej positif kepada penonton dan masyarakat luar dalam mengamalkan prinsip Rukun Negara bagi aspek Kesopanan dan Kesusilaan melalui animasi Upin \& Ipin. 
Kesejahteraan dan akhlak yang wujud dalam siri animasi ini telah membentuk satu semangat multibudaya yang kukuh terhadap seluruh warga komuniti Kampung Durian Runtuh. Sebagai contoh paparan babak ketika Mei Mei sedang menyampaikan sebuah cerita dalam kelasnya, terdapat kesalah perkataan yang diucapkan oleh Mei Mei dan telah diperbetulkan oleh rakan-rakan sekelasnya. Sikap saling menegur dan saling menerima ini merupakan sebahagian daripada akhlak dan nilai murni yang seharusnya diamalkan dalam kehidupan masa kini. Animasi Upin \& Ipin ini telah mengajarkan kepada kanak-kanak mahupun orang dewasa untuk sentiasa memupuk kesejahteraan dan amalan tolong menolong serta saling hormat menghormati antara satu sama lain. Hubungan antara individu dalam masyarakat akan menjadi harmoni kerana mereka tunduk di bawah peraturan yang sama iaitu kesopanan dan kesusilaan. Ini termasuk tanggungjawab bagi setiap individu kepada individu yang lain dengan memelihara akhlak yang baik dan menjauhi akhlak yang buruk.

Faktor pembentukan masyarakat berbilang kaum yang harmoni dapat dilahirkan sekiranya setiap individu dalam masyarakat boleh berpegang teguh kepada prinsip kelima ini. Antara faktor yang menyumbang kepada keruntuhan perpaduan adalah aspek pergaulan. Dalam masyarakat Malaysia, ada yang hanya bergaul sesama bangsa mereka sahaja dan tidak mahu untuk bercampur serta mengenali bangsa-bangsa lain. Ini akan menyukarkan proses untuk saling memahami dan mengenali perbezaan di antara kaum dan bangsa. Penghasilan animasi Upin \& Ipin merupakan satu usaha yang amat baik dan cemerlang dalam menyemai semangat perpaduan tidak kira di Malaysia mahupun di negara jiran seperti Indonesia, Singapura dan Brunei. Kanak-kanak yang menonton animasi ini akan dapat melihat suasana kehidupan masyarakat majmuk yang telah wujud sekian lama di negara mereka. Kehidupan masyarakat majmuk boleh sahaja diambil dan dilihat dalam animasi ini melalui episod seperti Skuad Bebas Denggi, di mana penduduk Kampung Durian Runtuh telah bersama-sama dalam menjalani program komuniti bebas Denggi di kawasan kampung mereka. Paparan babak ini dapat membentuk sebuah komuniti setempat yang mampu meluangkan masa bersama jiran tetangga mereka dalam menjaga kesejahteraan dan kebersihan kampung halaman mereka.

Pemerkasaan prinsip Rukun Negara kelima ini iaitu Kesopanan dan Kesusilaan sebagai asas perpaduan menjadi batu asas dalam hubungan etnik. Dalam siri animasi Upin \& Ipin ini menerusi episod Berpuasa Bersama Kawan Baru, suatu watak baharu telah diperkenalkan iaitu watak Susanti yang berasal dari Jakarta, Indonesia yang baru berpindah ke Kampung Durian Runtuh mengikut keluarga yang bertugas di daerah tersebut. Paparan setiap babak yang digambarkan menerusi kaca televisyen ini melihatkan penerimaan masyarakat Kampung Durian Runtuh terhadap tetangga baharunya yang mempunyai sedikit perbezaan daripada segi bahasa, budaya dan adatnya. Namun kehadiran Susanti dan keluarganya telah dapat diterima oleh penduduk kampung tersebut dengan hati yang terbuka kerana masyarakat yang baik adalah mereka yang mempunyai sifat terpuji dan baik hati.

Garapan daripada animasi Upin \& Ipin ini turut membantu dalam melahirkan masyarakat yang bersopan dan bersahsiah mulia, bermaruah, bertatatertib dan bertatasusila, selaras dengan kempen Budi Bahasa dan Nilai Murni yang dijalankan menerusi episod Terima Kasih Cikgu, Puasa, Nikmat dan Kawalan Pergerakan. Paparan sikap positif dan sikap bersopan santun serta bersusila patut diamalkan bagi membentuk seseorang individu dan masyarakat yang berdisiplin dan bermoral tinggi di mana melalui sikap ini ia secara langsung akan membantu mewujudkan sebuah masyarakat yang harmoni dan matang. Segala paparan yang baik telah dipersembahkan dalam siri animasi Upin \& Ipin agar menjadi panduan dan tauladan. Elemen penceritaan yang menggunakan prinsip-prinsip Rukun Negara yang diolah dalam bentuk penceritaan lebih mudah 
difahami oleh masyarakat apabila mereka menontonnya. Prinsip-prinsip ini menjadi panduan supaya perilaku masyarakat sentiasa terpelihara dan berkembang sesuai dengan keperibadian bangsa dan nilai-nilai murni seperti yang ditayangkan dalam semua episod animasi Upin \& Ipin.

Selain itu, saluran media masa turut memainkan peranan yang penting dalam pembinaan bangsa yang mematuhi prinsip Rukun Negara. Saluran media masa seperti televisyen, akhbar, filem, animasi dan laman sosial ini akan memberikan pendedahan kepada masyarakat berkenaan kepelbagaian berita, laporan dan dasar-dasar kerajaan bagi mengurangkan jurang maklumat yang wujud. Saluran media massa seperti siri animasi Upin \& Ipin turut dapat membentuk pemikiran dan pandangan rakyat dalam memahami kepelbagaian nilai dan simbol negara terutamanya yang berkaitan dengan Rukun Negara. Dalam montaj animasi Upin \& Ipin yang bertajuk Upin \& IpinRukun Negara, secara keseluruhannya animasi ini telah berjaya memupuk perpaduan dengan menerapkan prinsip Rukun Negara melalui teras yang kelima iaitu Kesopanan dan Kesusilaan. Paparan yang ditonjolkan dalam animasi Upin \& Ipin telah berjaya mewujudkan perpaduan, kefahaman dan integrasi nasional dalam setiap lapisan masyarakat kerana sikap kesederhanaan dan bertolak ansur telah wujud dalam semua kaum menerusi Kesopanan dan Kesusilaan.

\section{Kesimpulan}

Menerusi siri animasi Upin \& Ipin yang ditayangkan di kaca televisyen terdapat implikasi positif dalam kajian ini apabila ia menunjukkan pencapaian yang amat baik daripada penonton dalam menerapkan elemen Rukun Negara pada setiap episodnya menerusi jalan cerita yang dipaparkan kepada penonton secara tidak langsung. Oleh itu sebagai rakyat Malaysia, marilah bersama-sama rakyat menjunjung lima Prinsip Rukun Negara yang telah menjadi teras dalam kehidupan rakyat berbilang kaum di negara ini dalam menjalani kehidupan yang aman dan damai serta makmur bagi mengecapi perpaduan yang harmoni. Sebagai rakyat Malaysia, semua lapisan seharusnya memainkan peranan dalam menghargai dan memelihara erti kemerdekaan yang dimiliki ini secara berterusan dan berpanjangan.

Kajian ini diharapkan dapat membantu masyarakat di luar sana khususnya kanak-kanak dan orang dewasa untuk terus mengamalkan dan menerapkan konsep Rukun Negara dalam kehidupan mereka kerana segala prinsip yang digariskan ini merupakan perkara utama untuk mengecapi perpaduan dalam kalangan rakyat Malaysia iaitu Rukun Negara merupakan lambang jati diri dan pegangan serta panduan dalam mengukuhkan strategi perpaduan untuk terus menyatupadukan rakyat dalam cabaran mendepani pelbagai polemik politik dan sosial pada masa kini. Dengan berlandaskan Rukun Negara sebagai hala tuju kemakmuran negara, pastinya setiap lapisan masyarakat akan merasai nilai perpaduan yang lebih baik daripada sebelum ini. Semua rakyat harus memperjuangkan dan mempertahankan kelima-lima prinsip Rukun Negara demi mencapai perpaduan nasional dalam jiwa dan diri masyarakat Malaysia.

\section{Rujukan}

Ab Razak Ab Karim. (2006). Strategi komunikasi dan kesopanan berbahasa dalam kalangan masyarakat Melayu tradisional: kajian berdasarkan warkah-warkah Melayu lama. Persidangan Antarabangsa Pengajian Melayu. Kuala Lumpur, Universiti Malaya. 
Fadli Abdullah, \& Md Sidin Ahmad Ishak. (2010). Pembangunan sektor animasi di malaysia: pendidikan dan latihan animasi di Institusi Pengajian Tinggi Awam. Jurnal Pengajian Media Malaysia, 69-82.

Fatimah Muhd Shukri, \& Nur Afifah, V. A. (2016). Ruang, masa dan sebab akibat dalam naratif filem animasi Geng Pengembaraan Bermula. Jurnal Melayu, 15(2), 237-249.

Hadijah Johari, \& Anas Suzastri Ahmad. (2019). Persepsi terhadap konsep Rukun Negara melalui pengajaran kursus Pengajian Malaysia. E-Prosiding Persidangan Antarabangsa Sains Sosial dan Kemanusiaan 2019, Kolej Universiti Islam Antarabangsa Selangor.

Harsono, B. (2009). Perbedaan hasil belajar antara metode ceramah konvensional dengan ceramah berbantuan media animasi pada pembelajaran kompetensi perakitan dan pemasangan sistem rem. Jurnal Pendidikan Teknik Mesin, 9(2), 71-79.

Hasrul Hashim, Jamaluddin Aziz, \& Faridah Ibrahim. (2014). Filem dan revolusi teknologi: persepsi penggunaan CGI dari aspek estetik dan kreativiti. Jurnal Komunikasi, 30, 95-106.

Hassan Mutalib. (2006). The influence of anime on Malaysia animation filmakers. Kuala Lumpur, Rempah Seniman.

M. Mahmood. (2012). Kesinambungan tradisi dalam animasi. Kuala Lumpur, Dewan Bahasa dan Pustaka.

Mardiana Nordin \& Hasnah Hussin. (2014). Pengajian Malaysia. (Edisi Kelima). Selangor, Oxford Fajar.

Marlyna Maros. (2008). Lakuan bahasa komplen: manifestasi dan istilah-istilahnya dalam komuniti bahasa Melayu. Jurnal Melayu, (3), 1-20.

Mohammed Shahemey Azmi. (2015). Animasi Malaysia cetus fenomena. Kuala Lumpur, Utusan Melayu (M) Berhad.

Mohd. Nor Shahizan Ali, Mus Chairil Samani, \& Hasrul Hashim. (2011). Analisis naratif filem dokumentari The Kinta Story (1949). Jurnal Komunikasi, 27(2), 183-202.

Noor Hasnoor Mohamad Nor, Eizah Mat Hussain, \& Ahmad Ramizu Abdullah. (2019). kesopanan dalam komunikasi menerusi filem animasi kanak-kanak tempatan. Jurnal Komunikasi: Malaysian Journal of Communication, 35(4), 368-385.

Siti Norayu Mohd Basir, Junainor Hassan, Shuhairimi Abdullah, \& Hasad Hassan. (2004). persepsi pelajar terhadap konsep rukun negara melalui pengajaran subjek hubungan etnik:kajian kes di Universiti Malaysia Perlis. Journal of Human Development and Communication, 3 (Special Issue), 67-79.

Zuliskandar Ramli. (2011). Rumpun Melayu di Madagascar. Dlm. Nik Hassan Shuhaimi Nik Abd. Rahman, Zuliskandar Ramli, Mohamad Zain Musa, \& Adnan Jusoh (pnyt.). Alam Melayu satu pengenalan. Bangi, Institut Alam dan Tamadun Melayu (ATMA).

Zulkifley Hamid, \& Naidatul Zamrizan Abu. (2013). Memupuk perpaduan di Malaysia - santun bahasa dalam kalangan murid pelbagai etnik dari aspek penggunaan kata ganti nama diri. Geografia-Malaysian Journal of Society and Space, 31(1), 171-186.

Zulkifley Hamid, Naidatul Zamrizan Abu, \& Asyraf Zulkifley. (2015). Strategi komunikasi dalam kalangan murid pelbagai etnik. Jurnal Komunikasi, 31(1), 171-186. 